\title{
A LUTA PELOS DIREITOS HUMANOS: profissionalização de causas e politização do direito
}

\author{
Fernanda Rios Petrarca ${ }^{*}$
}

\begin{abstract}
Este artigo investiga a relação entre o exercício profissional do direito e os investimentos militantes na defesa dos direitos humanos. Trata-se de examinar, por um lado, as lógicas coletivas e situacionais que configuram a oferta militante no espaço profissional do direito e, por outro, as carreiras individuais, focando tanto na dimensão objetiva, ou seja, no conjunto de recursos sociais, políticos e profissionais de que dispõem os advogados, quanto na sua lógica subjetiva, envolvendo a redefinição ideológica com a profissão. A metodologia adotada consistiu em aplicação de questionários e realização de entrevistas biográficas com os advogados que atuam na área dos direitos humanos em Aracaju. Este trabalho permite demonstrar que experiência do engajamento em direitos humanos exerce um papel determinante para identificação profissional.

PALAVRAS-CHAvE: Direitos humanos. Investimento profissional. Ativismo jurídico. Causas sociais. Engajamento.
\end{abstract}

\section{INTRODUÇÃO}

A participação associativa é um fenômeno que vem crescendo no Brasil desde os anos 1990, com a redemocratização do país e com o aumento expressivo do número de entidades voltadas para fins diversos. De acordo com a última pesquisa realizada pelo Instituto Brasileiro de Geografia e Estatística (IBGE) e pelo Instituto de Pesquisa Econômica Aplicada (IPEA) a respeito das Fundações e Associações Sem Fins Lucrativos (FASFIL), o Brasil possui um montante de 338 mil entidades sem fins lucrativos, de acordo com a sua natureza jurídica, incluindo desde associações, fundações, organizações não governamentais até entidades de defesa de categorias profissionais e entidades religiosas. Desse total, cerca de 80 mil estão situadas no Nordeste, que corresponde à segunda maior região em número de entidades, perdendo apenas para o Sudeste. Além disso, os dados demons-

* Doutora em sociologia. Professora adjunta da Universidade Federal de Sergipe.

Av. Marechal Rondon s/n. São Cristóvão. Cep: 49000000. Aracaju - Sergipe - Brasil. f.petrarca@uol.com.br tram que $41 \%$ do total das entidades foram fundadas nos anos 1990 e estão voltadas para a defesa e promoção dos direitos dos cidadãos, incluídas nessa categoria as associações de moradores, comunitárias e de defesa de grupos e minorias. $\mathrm{Na}$ região Nordeste, o que se observa é um intenso crescimento das entidades e associações nos últimos 10 anos, sobretudo aquelas destinadas ao desenvolvimento e defesa dos direitos (defesa das minorias, defesa de grupos, associações de moradores, centros comunitários), em primeiro lugar. Em segundo, estão as associações profissionais e, em terceiro, as de caráter religioso.

Outra pesquisa que merece ser citada aqui é a da Associação Brasileira de Organizações Não Governamentais (ABONG), realizada em 2010. Tal pesquisa, diferentemente da anterior, circunscreve-se ao universo das entidades voltadas para a organização civil e que estão cadastradas na ABONG. De acordo com essa recente pesquisa, as causas sociais mais mencionadas nas bandeiras das organizações são as seguintes, nessa ordem: educação (48,9\%); organização e participação popular (33,8\%); defesa dos direitos das mulheres $(27,1 \%)$; 
e justiça e promoção de direitos (23,3\%). Portanto, se considerarmos a bandeira "defesa e promoção dos direitos", teremos um total de 50,4\% entidades incluídas na defesa dos direitos das mulheres e na defesa da justiça. Além disso, destaca-se como principal tipo de intervenção a articulação política e a chamada advocacy, com 71\%. Tal intervenção se manifesta no acionamento da esfera política e jurídica, assim como na luta pela promoção, ampliação e efetivação de direitos. A intensa ativação e a pressão feita às esferas política e jurídica, por exemplo, têm se constituído nos principais tipos de intervenção dessas associações. Assim, podemos perceber que o direito ocupa um lugar central nas novas formas de ação coletiva, em detrimento das formas mais tradicionais, tais como manifestações de rua, greves, ou ainda as estratégias para atrair a atenção da mídia. Como forma de pressão e de protesto, o direito se constitui como um instrumento eficaz de luta dos grupos e um importante argumento para expressar as injustiças e as reivindicações.

Diante desse panorama mais geral, podemos perceber a consolidação de um ativismo de direitos. Tal configuração permite o investimento e a atuação de um conjunto de atores sociais, dentre eles os advogados, que mobilizam o conhecimento jurídico na defesa dessas causas. Partindo dessas questões como fontes iniciais de indagação, este artigo analisa, mais especificamente, os profissionais do direito que, em nome de um conhecimento jurídico, atuam na defesa e promoção dos direitos humanos em Aracaju. Este trabalho faz parte de uma pesquisa mais ampla ${ }^{1}$ sobre a atuação profissional na defesa de causas sociais diversas, na qual constatamos um total de 22 instituições que contam com profissionais qualificados ocupando cargos técnicos, remunerados ou voluntários. Dentre os referidos profissionais, pode-se identificar um montante de 101, distribuídos em vinte formações diversificadas, com destaque para o direito, o qual corresponde a $32 \%$ do

${ }^{1}$ Esta pesquisa contou com o financiamento do CNPq Agradeço especialmente à bolsista de iniciação científica, Maria Rita Ribeiro, pelo intenso trabalho de coleta de dados realizado, e a Flávia Ferreira, membro da equipe e mestre em sociologia. universo. Além disso, 73\% do total de profissionais estão voltados para a defesa dos direitos humanos, a qual se constitui como a causa que mais agrega profissionais, sobretudo advogados.

Uma das questões que tem se destacado nas últimas décadas é o crescente número de pesquisas que apontam para a forma como a competência técnica e a formação acadêmica assumem um papel essencial no recrutamento e seleção de novos quadros militantes (Agrikolianski, 2002; Collovald, 2002; Meimon, 2004; Siméant, 2004; Sawicki; Siméant, 2012). Essas formas de recrutamento contribuem significativamente para novas modalidades de usos da profissão e do título universitário nas carreiras daqueles que se engajam na defesa de causas variadas, manifestada, sobretudo na atuação em causas urgentes, como a luta pelos direitos humanos, o combate à homofobia, a defesa dos grupos étnicos, a luta contra o câncer, a defesa do meio ambiente, dentre outras. Tais causas agregam profissionais especializados e capazes de colocar o seu saber técnico em prol da construção e da defesa de direitos. Nesse sentido, o investimento na defesa de causas humanitárias solicita recursos específicos, voltados tanto para atuação política quanto para a formação especializada, permitindo aos agentes ajustar suas competências profissionais aos objetivos pretendidos na defesa das causas.

Como se pode perceber, esse novo modo de ação profissional, o qual se constitui na relação entre as esferas profissional e as do engajamento e da militância, traz uma série de problemas analíticos para repensar a compreensão dos universos profissionais e as transformações pelas quais passam. Por um lado, é preciso questionar como as competências profissionais se ajustam aos objetivos da ação militante, contribuindo para estruturar o espaço da mobilização. Uma das maneiras de dar conta disso é analisando as conjunturas sócio-históricas e os contextos particulares, uma vez que eles criam ciclos de engajamento. Por outro lado, qual a base dos recursos sociais de que dispõem os agentes especializados para se engajar profissionalmente na defesa de causas humanitárias e como ocorre a retribuição da ação militante? Em outras palavras, 
quem são os profissionais prontos a investir na defesa de causas? E o que ganham com isso? Por fim, como as percepções do papel profissional se modificam e se ajustam às formas de engajamento, ganhando, desse modo, um sentido novo?

Diante disso, os trabalhos de Lochard e Simonet (2009) têm salientado que a principal característica desses profissionais é a intensa circulação em dois universos e a necessidade de fazer uso de dois "registros de legitimação", que são as competências profissionais e a ação política. Essa múltipla inserção exerce um papel importante nos processos de reelaboração da imagem do profissional e do sentido atribuído ao conhecimento especializado.

Com intuito de aprofundar a discussão, este artigo tem como objetivo principal demonstrar que a investigação das formas de engajamento associativo e profissional dos advogados constitui uma abordagem pertinente não só na apreensão das condições de acúmulo e reconversão de recursos profissionais em recursos políticos e militantes, mas também das percepções e dos "engajamentos de si". ${ }^{2} \mathrm{O}$ desafio principal deste texto é, portanto, partir da investigação das lógicas individuais sem ignorar um exame das lógicas coletivas e situacionais que constituem as carreiras.

Para dar conta de tal objetivo, aplicamos questionários e realizamos entrevistas biográficas com tais profissionais, com o intuito de observar tanto as condições objetivas do engajamento, quanto as percepções a respeito do exercício profissional e da militância, assim como as tomadas de posição, tanto no âmbito dos respectivos espaços de atuação profissional como em outros espaços sociais em que tenham atuado. O conjunto de problemas anteriormente citados nos permitiu organizar este texto em três eixos fundamentais. O primeiro permite apreender a dinâmica histórica e as lógicas macrocontextuais que estruturam a profissão jurídica e a oferta militante, afetando as maneiras de exercer o engajamento na defesa de causas e na atuação profissional. Trata-se, mais especificamen-

${ }^{2}$ Essa expressão é utilizada por Collovald (2002) para se referir à forma como o engajamento envolve uma redefinição identitária e uma mudança nas visões de si mesmo e do mundo. te, de compreender a configuração do espaço do direito, as mudanças que alteram sua estruturação e como a pauta dos direitos humanos se constituiu como uma forma de atuação dentro desse espaço profissional.

O segundo diz respeito a uma análise sociográfica a partir da qual buscamos mapear e caracterizar os advogados que investem na defesa dos direitos humanos em Aracaju. A preocupação central está voltada para o exame de algumas propriedades sociais, tais como as origens, os investimentos profissionais, a posição ocupada no espaço profissional, as militâncias anteriores, dentre outras, e como elas podem influenciar o engajamento individual.

E, por fim, procuramos, por meio dos percursos profissionais, analisar a dinâmica da carreira, as reconstruções biográficas, as mudanças nas formas de percepção da atividade profissional e militante. Esse eixo permite considerar, como já sublinharam em outros trabalhos Collovald (2002) eFillieule (2001), os “engajamentos de si”, as concepções de mundo e as reconversões ideológicas que empreendem os profissionais ativistas e que permitem dar sentido aos recursos acumulados. Portanto, não é a "competência técnica" em si mesma que interessa, mas como os percursos dos profissionais ativistas, suas inserções e experiências permitem mudar sua visão de si mesmo e do mundo, fazendo com que a formação técnica ganhe novo sentido.

\section{LÓGICAS SITUACIONAIS DO ATIVISMO JURÍ- DICONA DEFESA DOS DIREITOS HUMANOS}

A defesa dos direitos humanos no Brasil, de um modo geral, emerge no período de fechamento político, durante a ditadura militar, nos anos de 1970, e volta-se para a defesa dos presos políticos e a luta contra a tortura, uma vez que a violação dos direitos humanos se tornou um dos principais eventos políticos nesse período. ${ }^{3}$ Desempe-

${ }^{3}$ Os trabalhos de Vecchioli (2006) e Garlant (2003), respectivamente sobre o investimento dos advogados na luta pelos direitos humanos na Argentina e no Chile, demonstram, igualmente, o peso das ditaduras militares na América Latina para defesa dos direitos humanos e a ênfase na defesa dos presos políticos. 
nharam papel central tanto as redes nacionais de contestação política e de cooperação quanto as redes internacionais no processo de ampliação das causas dos direitos humanos e de defesa de presos políticos, manifestada na denúncia de torturas e prisões aos fóruns e comissões internacionais. No que diz respeito às redes nacionais, podemos observar o papel de instituições religiosas, principalmente da Igreja Católica, por meio de grupos como a Comissão Pastoral da Terra, Centros de Defesa dos Direitos Humanos, constituídos pela Conferência Nacional de Bispos do Brasil (CNBB), como também as novas lideranças sindicais (movimento sindical no ABC Paulista), as entidades estudantis e as instituições de representação profissional, como a Ordem dos Advogados do Brasil (OAB) e a Associação Brasileira de Imprensa (ABI) e, ainda, as campanhas nacionais, como a Campanha pela Anistia. A OAB teve um papel decisivo nesse processo, intensificando sua participação por meio das comissões de direitos humanos e na luta pela democratização (Oliveira, 1992).

Esses grupos e eventos formaram um espaço de contestação política que permitiu a articulação entre atores e a formação de elos entre eles para discussão a respeito dos direitos humanos. Em Sergipe, no final dos anos 1970, podemos observar a formação desse espaço por meio de alguns grupos, como a Sociedade de Direitos Humanos, criada em 1979, no Instituto Histórico Geográfico. Além disso, pode-se identificar o movimento estudantil, ${ }^{4}$ bastante ativo no contexto da ditadura militar, e as dioceses e pastorais sociais instauradas no interior do estado. Atuando, muitas vezes, de forma clandestina e driblando a repressão política, esses grupos favoreceram a aproximação entre militantes e lideranças, criando redes informais de articulação na luta contra a ditadura. As dioceses, por exemplo, atuaram, sobretu-

${ }^{4}$ O movimento estudantil em Aracaju era formado por estudantes secundaristas, especialmente do Colégio Atheneu, e o movimento universitário, com destaque para o Centro Acadêmico Silvio Romero, da Faculdade de Direito da Universidade Federal de Sergipe (UFS), e o Centro Acadêmico da Faculdade de Economia, também da UFS. Esses dois últimos disputavam o controle do Diretório Central dos Estudantes (DCE). do, na articulação dos agricultores e na formação dos sindicatos rurais, bem como na luta por justiça no campo. Mais tarde, com a redemocratização, essa luta se traduziu na defesa do direito à terra. A diocese de Propriá, no interior do estado, teve um papel importante na organização e articulação política por meio do Movimento de Educação de Base e das Comunidades Eclesiais de Base, contribuindo para a formação de lideranças e para criação do Centro de Direitos Humanos em Propriá, no final dos anos 1980 (França, 2004).

Dentre as redes nacionais que se destacam no Brasil, nesse contexto, podemos citar a fundação do Movimento Nacional de Direitos Humanos (MNDH), que surge no ano de 1982 com o objetivo de constituir uma rede nacional para intercâmbio de informações, denúncias e pressões às autoridades políticas. Tal movimento surge atrelado a outras redes constituídas pela atuação religiosa, sobretudo das Igrejas Católica e Protestante, bem como algumas instituições profissionais, como Associação Brasileira de Imprensa e a Ordem dos Advogados do Brasil, as quais atuavam contra a tortura de presos políticos e em favor da anistia. Sua matriz fundadora aparece associada à teologia da libertação, que teve como principal expoente lideranças da Igreja Católica. As principais organizações, nesse momento, aconteciam em dioceses e paróquias, o que contribuía para uma ampla participação da Igreja. Além disso, os primeiros articuladores do MNDH ou eram oriundos das Igrejas ou mantinham vínculos com setores religiosos. Segundo Brito e Silva (1999), cerca de 50\% dos fundadores pertenciam a movimentos ligados à Igreja, e os demais estavam dispersos entre movimentos sindicais, partidos políticos e outros movimentos. Um exemplo disso pode ser encontrado nos registros do primeiro encontro do MNDH, os quais mostram o apoio de autoridades religiosas católicas e luteranas como Dom Evaristo Arns (Cardeal Arcebispo de São Paulo) e Reverendo Alberico Baeske (pastor regional da Igreja Evangélica de Confissão Luterana do Brasil), além de membros de entidades profissionais, como o jurista Hélio Bicudo, que teve intensa atuação no movimento. 
Entretanto, o movimento, que inicialmente apresentava um forte caráter religioso, passou por profundas transformações no curso das décadas de 1980 e 1990. Nos anos 1990, intensifica-se um discurso mais técnico e político, fazendo com que os argumentos religiosos perdessem espaço. Entram em cena novos atores, tais como professores, advogados e assistentes sociais, voltados para a causa dos direitos humanos. Segundo dados produzidos pelo próprio movimento, em 1991, a maioria dos profissionais que atuava no movimento era, em primeiro lugar, constituído de professores, e, em segundo, de advogados. A participação dava-se da seguinte maneira: professores, 19,50\%; advogados, 12,60\%; operários, 9,04\%; agentes de Pastoral, 8,20\%; agricultores, $3,80 \%$; assistentes sociais, $3,33 \%$; e psicólogos, 0,95\%. Na região Nordeste, nesse período, $27 \%$ dos militantes desse movimento eram professores e $24,5 \%$ eram advogados; os demais estavam dispersos em diferentes categorias.

As décadas de 1980 e de 1990, com a redemocratização do país e com o processo constituinte, representam um momento de reconhecimento legal de várias normas internacionais e nacionais de direitos humanos e um momento de intensa tradução de problemas sociais em problemas jurídicos, em que se observa a emergência de novos direitos coletivos ${ }^{5}$ (mulheres, negros, crianças e adolescentes, homossexuais). Segundo Meili (2001), a defesa dos direitos humanos, no contexto pós-autoritarismo na América Latina, representou uma mudança no sistema legal, tornando-o mais acessível. O processo de elaboração da nova Constituição, em 1988, representa a formalização do reconhecimento dos direitos humanos e o processo de incorporação de instrumentos internacionais, ratificando acordos e tratados internacionais. A partir da carta constitucional, foram incorporados: a Convenção Interamericana para Prevenção e Punição da Tortura, de 1989; a Convenção sobre os Direitos da Criança, de 1990; o Pacto Internacional dos Direitos Civis e Políticos, de 1992; o Pacto In-

\footnotetext{
${ }^{5}$ Em outra oportunidade (Petrarca; Neves, 2011), discutimos a emergência de um direito racial e o papel da Constituição de 1988.
}

ternacional dos Direitos Econômicos, Sociais e Culturais, de 1992; a Convenção Americana de Direitos Humanos, de 1992; a Convenção Interamericana para Prevenção, Punição e Erradicação da Violência contra a Mulher, em 1995. Além disso, foram criados: o Programa Nacional de Direitos Humanos, em 1996, o qual reconheceu formalmente os direitos humanos de "mulheres, negros, homossexuais, populações indígenas, idosos, deficientes físicos, refugiados, indivíduos infectados pelo HIV, crianças e adolescentes, policiais, prisioneiros, ricos e pobres"; e a Secretaria Nacional de Direitos Humanos, bem como os programas de ações afirmativas voltadas para o ensino superior. É ainda nesse período que se observa a formação de redes nacionais que visam à integração e articulação entre entidades e organizações não governamentais (ONGs) de direitos humanos de diversas regiões do país (fóruns, comitês)

Assim, observa-se uma definição mais ampla da questão dos direitos humanos que não inclui apenas os direitos políticos. O que acontecia até os anos 1970 era uma defesa mais voltada para os direitos políticos e civis; já nas décadas seguintes, as redes de defesa dos direitos humanos se diversificam e os esforços se concentram na defesa também dos direitos das populações marginalizadas, como direito à moradia, à saúde, à terra, ao transporte, etc. Esse é o momento também em que os advogados passam a investir na tradução de problemáticas construídas no âmbito dos movimentos sociais para o universo do direito.

Esse conjunto de mudanças está associado, em certa medida, à Constituição de 1988, a qual tem sido apresentada como um momento favorável para a emergência da diversificação do direito e para o surgimento de novas formas de atuação dos advogados no espaço político, permitindo novos usos do direito (Engelman, 2006). A Constituição abriu espaço para as demandas dos grupos, permitindo uma acessibilidade dos movimentos ao sistema jurídico. Contudo, esse modelo das "oportunidades jurídicas" não é suficiente para compreender os usos militantes do direito. É preciso ainda destacar, como salienta Agrikolianski 
(2010), o lugar que ocupa o direito nas formas de ação coletivas e quem são os profissionais do direito capazes de mobilizar a linguagem do direito e acionar a justiça.

Consequentemente, a abertura política e o processo de redemocratização possibilitaram também uma proliferação de causas e movimentos sociais, os quais passaram a contar com atores oriundos de vários segmentos, profissões e origens sociais. O que se observa, nesse momento, é uma diversidade não só nos temas, mas também nas características dos militantes, como demonstra Oliveira (2009), no caso do movimento ambientalista. Isso pode ser visto na ampliação de temas e causas voltadas para a questão dos direitos humanos, que ganham destaque nesse cenário, e na diversificação dos atores que passam a investir no espaço da mobilização humanitária. Uma das características que tem sido apresentada a esse tipo de investimento profissional está associada à assessoria prestada para os movimentos sociais. Como tem demonstrado a literatura, as assessorias técnicas representam, atualmente, uma das possibilidades de ampliação da atuação profissional, contribuindo para a “expansão horizontal” da profissão, ou seja, uma combinação entre exercício profissional e outras formas de atuação (Coradini, 2006).

Além dos movimentos se diversificarem nesse momento, como dissemos acima, tanto no que diz respeito às características dos militantes, quando nos tipos de intervenção e causas sociais, as associações profissionais também intensificam sua ação e institucionalizam as formas de intervenção. Um dos exemplos disso é a criação das comissões de direitos humanos pela OAB nacional e a autorização para as sedes regionais formarem suas próprias comissões. A criação dessas comissões contribuiu para criar um espaço institucional de intervenção para os advogados. No caso de Sergipe, especificamente, a primeira comissão de direitos humanos foi criada em 1981, momento em que a $\mathrm{OAB}$ autoriza suas regionais a instalar e criar suas próprias comissões locais, seguindo os moldes da comissão do estado do Rio de Janeiro, a qual contava com assistência jurídica. Entretanto, apesar da sua criação nesse período, ela só vai efetivamente funcionar no final dos anos 1980 e início dos anos 1990. A organização interna por meio de regimentos e as subdivisões em coordenadorias só ocorrem em 1998. Atualmente, a comissão está organizada em três coordenadorias permanentes: direitos humanos (composta pelas seguintes subcoordenadorias: atividade policial e penitenciária, saúde pública, defesa dos direitos dos grupos vulneráveis e direito da infância e juventude); diversidade sexual; e igualdade racial.

O material levantado sobre os registros das denúncias de crime contra os direitos humanos, na OAB de Sergipe, permitiu revelar que o maior número de denúncias está voltado para tortura praticada por policiais e delegados, assim como prisões ilegais e abuso de autoridade por parte da polícia (civil e militar). Mesmo com o término da ditadura militar, esse período ainda é marcado por uma violenta e hostil força policial. Na década de 1990, de 85 casos de denúncia registrados, 41 tratavam de abuso de autoridade policial. Os demais se dividiam em denúncias sobre racismo, homofobia e outros de natureza diversa. Na década seguinte, até 2003, cai o número de denúncias sobre racismo e homofobia e se mantêm ativas aquelas voltadas contra policiais. O grande número de denúncias sobre policiais e a significativa queda de temas como racismo e homofobia estão associados às modificações no espaço dos movimentos sociais. No final da década de 1990 e início da de 2000, o movimento negro e as associações de defesa dos homossexuais passam por uma intensa reelaboração, tanto na organização interna das ONGs quanto nos espaços que acionam na luta contra injúria racial e homofobia. Além da extinção de muitos grupos, observa-se que há uma diversificação do espaço de militância, e os grupos passam a contar com outras formas de reivindicação. No caso do movimento negro, alguns trabalhos destacam (Neves, 2000; Souza, 2009) que a entrada de alguns líderes na esfera estatal por meio das comissões e conselhos contribuiu para um esvaziamento e desarticulação do movimento.

Além da atuação dos advogados na defesa 
dos direitos humanos em espaços institucionais de representação profissional, os movimentos sociais em Sergipe também oferecem algumas possibilidades de engajamento e investimentos profissionais. Na falta de estudos sobre a configuração dos movimentos sociais em Sergipe, nosso levantamento, ainda que incipiente, permitiu verificar que a década de 1980 constitui o momento de emergência de um conjunto de associações e movimentos voltados para causas coletivas, sobretudo a questão racial e a defesa dos homossexuais. As décadas seguintes configuram-se, por um lado, pelo intenso esvaziamento de alguns grupos que não conseguem se adequar às mudanças que perpassam o movimento, por outro lado, pela profissionalização de outros por meio de financiamentos e projetos desenvolvidos junto à esfera estatal. Esse último é o caso das associações que se articulam em torno de projetos, como aqueles voltados para a questão da AIDS, das comunidades quilombolas, da defesa da criança e do adolescente, da violência contra a mulher, da luta contra homofobia e que passam a contar com o investimento da esfera estatal. ${ }^{6}$ A década de 2000 configura um momento de intensa organização do Estado por meio de fóruns, coordenadorias, comitês,

${ }^{6}$ São várias as organizações que surgem nesse período e que se profissionalizam contando com intensos recursos estatais. Dentre elas, podemos citar: o Movimento Popular de Saúde (MOPS), fundado em 1989 por uma enfermeira, voltado para a melhoria dos serviços públicos e a luta pela saúde, atualmente inserido no Fórum Permanente ONG/ AIDS, apoiado pela Secretaria da Saúde do Estado de Sergipe; o Grupo de Apoio à Prevenção da AIDS (GAPA), fundado em 1991 por um médico e por um grupo de advogados, altamente capacitada com recursos públicos e vinculada a programas governamentais como o DST/AIDS; a Associação de Travestis Unidas pela Cidadania (UNIDAS), fundada em 1999; Associação Sergipana de Transgêneros (ASTRA), fundada em 2001, que realiza atendimento médico e assessoria jurídica; a Associação de Defesa Homossexual de Sergipe (ADHONS), fundada em 2003. Estas três últimas são capacitadas com recursos financeiros do Programa DST/AIDS do governo federal. Além dessas, podemos citar o Instituto Braços, fundado em 2006, voltado para a temática do direito da criança, que está fortemente integrado aos fóruns, conselhos e projetos estatais, como os Conselhos municipal e estadual da Criança e do Adolescente e o Fórum Estadual de Defesa do Direito da Criança e do Adolescente, atualmente, presidido por um advogado. Seu orçamento anual gira em torno de R\$ 800.000,00. Além do Instituto Recriando, fundado em 2002, que atua na promoção dos direitos da criança com foco na produção de mídias e comunicação, inserido nas mesmas redes formais do Instituto Braços e em redes nacionais como a Agência de Notícias da Infância (ANDI). Seu orçamento anual gira em torno de $\mathrm{R} \$ 78.000,00$. centros, conselhos, secretarias, projetos, na defesa de causas humanitárias e na articulação com os movimentos sociais. Assim, o Estado oferece também possibilidades de investimento profissional nessa área, uma vez que ele vai funcionar tanto como um espaço de atuação de técnicos e especialistas na defesa das referidas causas, cooptando profissionais e militantes, quanto como um dos grandes financiadores de projetos. Essas mudanças, associadas aos financiamentos, afetaram a maneira de se engajar nas causas sociais, constrangendo as carreiras individuais e contribuindo para legitimação de novos militantes, sobretudo aqueles portadores de títulos universitários e membros de profissões específicas, tais como os advogados.

No que diz respeito às atuações relacionadas à temática dos direitos humanos na esfera estatal, pode-se observar que é somente a partir de 2007 que o governo do Estado de Sergipe tomará um posicionamento oficial na defesa dos direitos humanos, com a adesão ao Plano de Ações Integradas para Prevenção e Combate à Tortura no Brasil, assim como a instituição do Conselho Estadual de Defesa dos Direitos da Pessoa Humana em Sergipe. Antes disso, as iniciativas estavam concentradas na defesa dos direitos da criança e do adolescente (conselhos municipais e estaduais, fóruns, comitês), na luta contra a discriminação racial e contra a homofobia (Centro de Combate à Homofobia).

Como se pode perceber, as iniciativas dos advogados voltados para essa temática estão associadas, por um lado, por meio da criação das comissões de direitos humanos da Ordem dos Advogados Brasileiros (OAB/Sergipe), nas quais se inserem os direitos raciais, a defesa de pessoas com deficiência, etc.; por outro lado, pela atuação isolada em algumas entidades destinadas à defesa de categorias socialmente excluídas, como os grupos de defesa das mulheres, dos homossexuais, dos negros, que contam com alguns advogados. $\mathrm{E}$ podemos, ainda, perceber o investimento em comitês, comissões e conselhos organizados pelo Estado. Vale destacar que o investimento dos advogados em movimentos sociais, na qualidade de assessorias jurídicas, depende da configuração 
própria dos movimentos sociais no estado de Sergipe. O que se observa é que os movimentos que mais acionam advogados, e profissionais em geral, estão voltados para o direito da criança e do adolescente e a luta contra a homofobia. Tal situação está associada à configuração própria das entidades que lutam por essas causas e que, como destacamos, são as que mais se articulam em torno de projetos vinculados à esfera estatal. Essa estruturação dos movimentos sociais exerce um efeito na composição das próprias comissões da Ordem dos Advogados, em Sergipe, as quais respaldam as causas das organizações mais ativas.

Assim, a possibilidade de uma advocacia engajada na defesa de causas sociais está diretamente relacionada à estruturação do espaço jurídico e à configuração dos movimentos sociais. As modificações e as formas de organização desses espaços oferecem as condições de realização de carreiras constituídas pela dupla relação entre profissão e política. Tais questões nos permitem entender a formação de um "espaço de possibilidades" para a advocacia de causas.

\section{LÓGICAS OBJETIVAS DO ENGAJAMENTO NA DEFESA DE CAUSAS}

Como dissemos no início deste texto, podemos verificar, com base nos dados levantados, que a defesa dos direitos humanos é a causa que mais agrega profissionais, de um modo geral, em Sergipe. Em segundo lugar, está a luta contra o câncer e, em terceiro, a defesa do meio ambiente. A atuação profissionalizada se manifesta na qualidade de técnicos em instituições filantrópicas e organizações não governamentais que atuam no auxílio a essas causas, bem como em comissões e redes formais organizadas por instituições profissionais, como a Ordem dos Advogados de Sergipe, e pela esfera estatal. No caso especificamente da defesa dos direitos humanos, a defesa da criança e do adolescente é a que mais se destaca, seguida do combate à homofobia e da luta contra o racismo.

Éinteressante observar também que, em algu- mas causas, como a defesa do direito da criança e do adolescente e a luta contra o câncer, podemos identificar um conjunto de associações e grupos mais profissionalizados e fortemente institucionalizados, o que permite configurar, assim, uma situação de intensa oferta aos profissionais. Nessa linha, podemos citar algumas iniciativas que ilustram essa situação, como a do Instituto Braços, que realizou, recentemente, uma seleção para contratar profissionais de diversas áreas, como serviço social e direito, para atuar no âmbito de um projeto financiado pela Petrobrás através do Fundo Estadual dos Direitos da Criança e do Adolescente. ${ }^{7}$ Além disso, podemos perceber, no caso da luta contra o câncer, duas associações que se destacam nesse aspecto: a Associação dos Voluntários a Serviço da Oncologia em Sergipe (AVOSOS) e o Grupo de Apoio a Crianças com Câncer (GACC). A AVOSOS possui um quadro de 42 funcionários que integram várias equipes, e, dentre as atividades técnicas, destacam-se médicos, dentistas, nutricionistas, assistentes sociais e psicólogos. Além de contar com o apoio financeiro de empresas públicas e privadas, ${ }^{8}$ possui aproximadamente 158 voluntários em diferentes áreas e uma sede própria capaz de prestar atendimento a 300 pacientes. OGACC possui aproximadamente 32 funcionários que formam várias equipes, dentre as quais estão as equipes técnicas, voltadas para o atendimento médico de aproximadamente 50 pacientes. ${ }^{9}$

Do conjunto de 101 profissionais engajados na defesa de causas e cadastrados no momento inicial da pesquisa, conseguimos atingir um total de 60 deles conquistando, portanto, $60 \%$ do universo, para os quais aplicamos um questionário detalhado, organizado em torno de três eixos: ori-

7 O projeto, denominado "Estado de Direitos”, recebeu um montante de $R \$ 628.940 .00$. Na seleção, realizada para contratação de profissionais para atuar no projeto, foram abertas sete vagas, cinco delas para graduados na área de direito, serviço social e ciências humanas e dois para graduandos na qualidade de estagiários, com salários que variam entre $\mathrm{R} \$ 640,00$ e $\mathrm{R} \$ 1.300$ para graduados. Só em projetos, essa ONG conta, atualmente, com um montante de R\$ 812.000.00, distribuídos em quatro projetos diferentes. Ver em: http://www.institutobracos.org.br/ artigoestatico/3

${ }^{8}$ Isso ocorre, principalmente, por meio de editais de projetos do governo federal, como também do investimento de empresas privadas locais, como grandes construtoras.

${ }^{9}$ Sobre o associativismo na luta contra o câncer em Sergipe, ver Sousa (2010) 
gens sociais (profissão, escolaridade e engajamento político e partidário dos pais e avós); percurso escolar e trajeto profissional; e inserção política e militante. Com esse material, podemos identificar as áreas de formação que mais concentram os profissionais. O destaque é dado, principalmente, para a formação em direito, correspondendo a $40 \%$ dos casos investigados, e as áreas da saúde, sobretudo medicina e enfermagem, com 31,8\% (medicina, enfermagem, nutrição, educação física e biologia). Dos $40 \%$ formados em direito, todos estão inseridos na causa dos direitos humanos. Tal concentração depende, como dissemos acima, de um conjunto de lógicas situacionais e contextuais, uma vez que a ampliação do espaço do direito, no que diz respeito à atuação profissional na defesa dos direitos humanos, contribui para uma maior inserção profissional na esfera da militância, permitindo, assim, a formação de um espaço de atuação profissional engajado. Além disso, trata-se de cursos com uma maior aplicabilidade prática, o que contribui para intensificar a atuação no espaço das defesas de causas em defesa de direitos.

Do mesmo modo, identificamos que, daqueles profissionais que atuam na defesa dos direitos humanos, 70\% têm formação em direito, e os demais se dividem em profissões bastante diversificadas, como letras, ciências sociais, história, serviço social, jornalismo. Iremos tratar, nos tópicos seguintes, das características sociais, em termos de origens, investimentos profissionais e engajamento militante, dos advogados comprometidos com a defesa dos direitos humanos, com o intuito de identificar a base de recursos de que dispõem para investir nessa causa.

No que diz respeito às origens sociais dos advogados engajados na defesa dos direitos humanos, foram utilizadas três variáveis: grau de escolarização, profissão, e participação política dos pais. Pode-se perceber, quanto à escolaridade dos pais uma grande variação: 33,4\% concluíram ou iniciaram o curso de graduação; $25 \%$ possuem o ensino médio completo ou curso de nível técnico, tais como os oferecidos por escolas técnicas; $20,8 \%$ possuem apenas o fundamental; e 20,9\% possu- em o ensino fundamental incompleto ou nenhum grau de escolaridade.

Contudo, esse dado precisa ser relacionado com a profissão do pai. No que tange a esse aspecto, nota-se que a maior concentração está nas atividades manuais, sobretudo aquelas que não exigem uma qualificação técnica determinada ou formação universitária, e no pequeno comércio, correspondendo a um montante de $37,8 \%$. Esse é o caso das atividades como pedreiro, servente, pequeno comerciante, barbeiro, dentre outras. Em seguida, profissionais que atuam de acordo com sua formação universitária, sobretudo as atividades liberais, como medicina e as engenharias, com 29,4\%. Por fim, estão os técnicos, tais como técnico agrícola, técnico em edificações, com 16,8\%. Há ainda percentuais pequenos de professores $(4,2 \%)$, servidores públicos (8,3\%) e industriários (4,2\%).

No que diz respeito às origens sociais maternas, os dados se mantêm: $41,6 \%$ das mães iniciaram ou concluíram o ensino médio; 33,4\% possuem ensino fundamental completo ou incompleto; $25 \%$ iniciaram ou concluíram o curso de nível superior. Quanto à profissão das mães: as donas de casa constituem a maior parte ou $29,2 \%$, seguida do professorado com 20,8\%; e as atividades manuais, tais como cabeleireira, costureira representam 16,7\% do universo pesquisado. Além dessas, também encontramos atividades relacionadas à área da formação acadêmica e funcionalismo público, ambas com 16,7\%.

No que tange à participação política, optamos por agregar os dados do pai e da mãe na mesma variável, uma vez que ela nos permite medir o nível de participação do grupo familiar de origem. Com base nisso, podemos afirmar que 50\% dos pais dos advogados tinham algum tipo de participação política, em partidos, sindicatos, cooperativas ou associações. O destaque é dado para entidades de representação profissional, como sindicatos, e associações religiosas. Além disso, tal participação manifestava-se pelo engajamento nas atividades e eventuais ocupação de cargos, como presidente de sindicato, secretário, coordenadora de pastorais, dentre outras. 
Portanto, no que concerne às origens sociais, podemos perceber uma forte heterogeneidade, o que nos permitiu identificar pelo menos dois grupos. O primeiro grupo constitui a maioria do universo e é composto por pais com grau de escolaridade médio e alto, com ensino médio completo e formação acadêmica e profissões que exigem ou um conhecimento técnico apreendido em cursos profissionalizantes, ou conhecimento especializado obtido por meio do ensino superior. O segundo com baixa escolaridade, fundamental incompleto ou sem escolaridade alguma, desempenhando atividades manuais que não exigem grau de qualificação, tais como alfaiate, barbeiro, caminhoneiro, sapateiro, pedreiro. Consequentemente, tal situação se manifesta no nível de participação política dos pais. Aqueles que se situam no primeiro grupo apresentam um maior grau de participação política, divididos entre associações religiosas, sindicatos e cooperativas; em contrapartida, a participação política dos que estão inseridos no segundo grupo é baixa.

Entretanto, apesar de haver uma heterogeneidade, nossa investigação permitiu levantar alguns elementos comuns importantes. $\mathrm{O}$ primeiro deles se refere à trajetória do grupo familiar. Podemos perceber que se trata de uma trajetória ascendente, uma vez que, em $50 \%$ dos casos, os avós maternos e paternos exerciam atividades manuais, sem exigência de qualificação, tais como caixeiro viajante, agricultor, motorista, pequeno comerciante, dentre outros. E a análise apresentada anteriormente nos permite afirmar que a maioria dos pais apresentou uma mobilidade intergeracional, ocupando posições no mercado de trabalho mais estáveis e com grau de qualificação técnica, se comparados à geração dos avós. O segundo aspecto é concernente à participação política dos pais dos entrevistados. Por meio dela, podemos identificar que o engajamento religioso constitui a principal atividade militante.

O engajamento religioso tem sido apresentado pela literatura sobre militância como importante meio de ingressar e desenvolver um "gosto" pela participação, uma vez que ele se caracteriza por um tipo de ação altruísta de solidariedade e ajuda aos outros, aos desfavorecidos, aos carentes (Passy, 1998; Siméant, 2004). Assim, estar exposto a essas mensagens, vivenciar, compartilhar e ser socializado nesse tipo de ação contribui para formar as bases sociais para o engajamento. Desse modo, percebe-se que a participação e a atuação dos pais em instituições religiosas constitui um importante mecanismo de composição dos antecedentes sociais que poderiam servir como alavancas ou estimuladores da militância. Em outras palavras, funcionariam como disposições sociais para o engajamento na defesa de causas.

Outra dimensão objetiva importante aqui está associada aos investimentos profissionais dos entrevistados. Para isso tratamos das seguintes variáveis: titulação acadêmica, ocupação principal, inserção profissional, período de formação, títulos de pós-graduação. Do total daqueles que atuam na defesa dos direitos humanos, 70\% têm formação em direito, e as demais formações são pedagogia, jornalismo, serviço social, ciências sociais. Ainda com relação ao conjunto daqueles que se voltam para tais causas, $63,6 \%$ ocupam cargos não remunerados na defesa e no engajamento nas causas. Vale lembrar que esse alto índice está associado ao fato de que se trata de cargos ocupados, na sua grande maioria, como representantes de comissões voltadas para os direitos humanos em instituições como a Ordem dos Advogados do Brasil de Sergipe, conselhos municipais e estaduais.

No que diz respeito à ocupação principal, entendida aqui como o emprego a partir do qual a vida profissional está centrada, foi possível perceber que o exercício da advocacia particular em escritórios constitui a atividade que mais se destaca, correspondendo a 70,8\%, seguido de carreiras jurídicas estatais (procurador, delegado, defensor público), com 16,7\% e assessoria jurídica, com $12,5 \%$. Além disso, no caso daqueles cuja atividade principal está concentrada em escritórios de advocacia, essa atuação é concomitante a outras, como eventuais assessorias e consultorias jurídicas e o exercício do magistério em faculdades particulares de direito. Este dado é particularmente relevante porque permite revelar que o investimento 
na defesa dos direitos humanos agrega advogados cuja atuação está pautada na defesa de clientes.

Do mesmo modo, esse dado, associado à faixa etária e ao período de formação acadêmica, permite caracterizar melhor o universo. A faixa etária que se destaca é a que vai dos 22 até os 32 anos, com $38 \%$ e o período de formação se concentra entre 2001 e 2010, com 58,4\%. Os demais se subdividem em categorias bastante distanciadas de idade e ano de conclusão da graduação. Além disso, a posição no universo profissional desse grupo de jovens recém-formados é, especialmente, a advocacia privada e a assessoria jurídica. Portanto, trata-se de advogados recém-formados, que estão investindo no direito via escritórios particulares, intensificando seus investimentos profissionais em várias frentes, como assessorias jurídicas e exercício do magistério. E a defesa dos direitos humanos manifestada, seja pela atuação nas comissões da $\mathrm{OAB}$, seja pela participação em movimentos sociais, representa uma dentre as atividades secundárias com as quais se envolvem. Isso revela um multipertencimento e um intenso investimento concomitante em vários espaços. Esse múltiplo investimento e a diversidade de atuação têm se revelado como uma condição importante em situação de não emprego, uma vez que contribuem significativamente para ampliar os contatos e as redes de relações que podem ser mobilizadas em determinadas situações.

No que diz respeito ao investimento na formação profissional, podemos identificar que $58 \%$ dos entrevistados possuem pós-graduação, sendo o nível de especialização o mais alto, correspondendo a $54 \%$. Contudo, o que se percebe é que a especialização está direcionada para vários campos do direito, como direito do trabalho, direito civil, direito previdenciário, direito público. Isso está associado, por um lado, ao fato de que a pós-graduação na área dos direitos humanos em Sergipe foi criada em 2009, portanto em um período recente; e, por outro, à percepção de que a atuação na defesa da causa humanitária representa uma possibilidade de investimento profissional dentre muitas outras que se apresentam aos advogados. Assim, a defesa dos direitos humanos diversifica as formas de atuação profissional e intensifica os múltiplos investimentos e pertencimentos profissionais. Além disso, é importante também relacionar esse dado com o momento de entrada no universo da defesa de causas. Desse modo, foi possível identificar que, daqueles que possuem pós-graduação, os seus investimentos na qualificação profissional começaram concomitante ao exercício da militância na defesa de causas. Associada a isso está a variável que nos permite medir o índice de inserção profissional. Através dela, foi possível perceber que a entrada no universo de causas humanitárias amplia as possibilidades de investimento profissional, uma vez que a maioria dos advogados, cerca de $70 \%$ deles, ampliou a ocupação de cargos em outros setores depois que começou sua participação na defesa dos direitos humanos em movimentos sociais ou em associações profissionais. Isso se manifesta na ocupação de cargos de chefia no seu setor de atuação profissional, assim como diversificação de assessorias e consultorias jurídicas e indicações como representante dos direitos humanos.

Pode-se constatar, ainda, que a militância em movimentos sociais conduz ao acúmulo de recursos que podem ser usados para ampliar os investimentos profissionais e políticos, permitindo, inclusive, o acesso ao mercado de empregos (Gaxie, 2005). Dessa forma, o exercício profissional em "causas sociais e coletivas" é, particularmente, pertinente à análise dos usos da "competência profissional" para investimento na esfera militante e dos usos da "competência militante" para os investimentos profissionais. A inserção no mercado de empregos se constitui em um grande estimulador do engajamento, configurando uma nova situação no mercado de trabalho profissional. Nesse sentido, o engajamento na defesa de causas permite ampliar as possibilidades de investimentos profissionais, permitindo, inclusive, o acesso à esfera do trabalho.

Pode-se perceber que, ao analisar algumas variáveis quanto ao engajamento desses profissionais em outras esferas da militância, como o movimento estudantil, a participação política e filiação 
partidária e a atuação em movimentos sociais, foram encontrados os seguintes resultados. Do conjunto dos advogados que defendem os direitos humanos, 54\% não participou do movimento estudantil; os $46 \%$ que participaram estão divididos da seguinte forma: em centro acadêmico (30\%); grêmio estudantil (4\%), e mais de uma instituição (12\%). Assim, o universo acadêmico se torna um importante estimulador da participação política, constituindoum meio de entrada na militância e no engajamento na defesa de causas relativas à defesa de direitos.

Podemos, ainda, verificar a participação prévia desses advogados, considerando a atuação anterior em movimentos sociais, associações e organizações não governamentais, e podemos perceber que $70 \%$ não apresentam engajamentos anteriores em movimentos sociais de natureza diversa. No que diz respeito à filiação partidária, os dados se mantêm, e a maior parte, $76,5 \%$, dos questionados, não participa de partidos políticos.

Podemos identificar, desse modo, alguns grupos no que diz respeito aos engajamentos prévios como uma condição importante para o recrutamento, uma vez que tais engajamentos representam a inserção em redes de participação e o acionamento de contatos, relações importantes que podem funcionar como estimuladores da participação profissional na defesa das referidas causas. Além disso, esses investimentos prévios contribuem para reorientar as perspectivas profissionais e funcionam, muitas vezes, como reconversões ideológicas, uma vez que, neles inseridos, os indivíduos estão expostos a um conjunto de imagens e discursos que contribuem para dar sentido e orientar as perspectivas. O primeiro grupo, que corresponde à grande maioria, é composto por aqueles que não possuem uma participação prévia no universo da militância, seja ele acadêmico, político partidário ou em instituições e ONG's; o segundo é composto por aqueles que possuem uma participação política anterior manifestada pela inserção no movimento estudantil e consequente inserção na participação política partidária e atuação no universo das ONG's e outras instituições e associações que atuam na defesa das causas hu- manitárias e sociais. É possível ainda destacar aqueles que só tiveram como participação prévia o investimento no movimento estudantil.

Outra variável que se destaca aqui é aquela que permite questionar como o entrevistado entrou em contato com a causa em que atua. Do conjunto, apenas $16 \%$ entraram em contato via participação em outros movimentos sociais. A grande maioria, cerca de $40 \%$, afirmou que entrou em contato via amigos do espaço do trabalho ou colegas da universidade. Além disso, cerca de $60 \%$ encontraram incentivos para atuar profissionalmente na defesa de tais causas em amigos e colegas de trabalho. Podemos ainda destacar que, dentre os fatores citados para a conquista do cargo profissional na instituição, estão convites e indicações de amigos (da universidade, de outros movimentos sociais) e colegas de trabalho, com 30\% do total. Construímos, de um lado, cinco categorias de laços sociais: amigos, colegas de trabalho, família, membros de outros movimentos sociais e universidade. De outro, destacamos aqueles que entraram no movimento via a publicização da mídia e outros motivos (destacam-se, nesse caso, motivos pessoais, tais como doença na família)

O que se percebe, nesses casos, é o peso dos laços sociais para o engajamento individual, quer sejam eles obtidos no interior das relações familiares, quer sejam construídos no espaço do trabalho ou das relações de amizade derivada da múltipla inserção. Segundo MacAdam e Paulsen (1993), as pesquisas sobre os movimentos sociais há muito tempo vêm apontando para o peso dos laços sociais no recrutamento e engajamento individual, mais especificamente o peso dos laços constituídos por redes de relações anteriores com o movimento como um elemento fundamental para a entrada e engajamento no ativismo. Tais laços com membros de organizações constituem importantes estimuladores da ação coletiva. Assim, o que se percebe é que os advogados, na defesa dos direitos humanos, estão envolvidos em uma multiplicidade de laços sociais (amigos, familiares, colegas) que os conduzem ao ativismo.

Além disso, um número considerável, 40\%, 
conquistaram cargos de chefia devido à sua inserção profissional na defesa das causas, ampliando, assim, sua atuação. Desse conjunto, $12 \%$ ocupam tais cargos atualmente em ONGs e $88 \%$ em instituições públicas que se dedicam à atuação na defesa de causas sociais.

Outra variável importante, que nos fornece elementos para a compreensão do engajamento militante, é a participação em outras organizações, associações filantrópicas e conselhos, além da formação de redes decorrentes disso. Conseguimos medir o nível de participação política desses entrevistados e verificamos que todos aqueles que defendem a causa dos direitos humanos têm um alto nível de participação, uma vez que estão inseridos em mais de um espaço de defesa. É também na causa dos direitos humanos que podemos verificar um número maior de participações quando comparada a outras causas, como aquelas voltadas para a luta contra o câncer ou para a defesa do meio ambiente. Podemos identificar que, entre os advogados, essa inserção é ainda maior, correspondendo a $50 \%$ inseridos em mais de três espaços de defesa; $25 \%$ em mais de 4 espaços e $12 \%$ em mais de 5 . Comparando esses dados com os anteriormente apresentados, podemos afirmar que a inserção na defesa dos direitos humanos amplia os níveis de participação, aumentando as chances de multiplicar os espaços de defesa. Isso porque tal inserção possibilita o acesso a outros espaços e universos antes não acessados.

Desse modo, buscamos, neste ponto, demonstrar alguns indicadores de redes, sejam elas as redes formais ou informais. Primeiro, temos como redes formais a participação do indivíduo como membro de um movimento social ou de organizações e associações filantrópicas, seja como voluntário, seja como membro do quadro da organização. Os indicadores que se prestam para isso estão relacionados à participação em outros movimentos sociais, bem como ao tipo de participação (ativista, membro do quadro da organização, simpatizante). Segundo, procuramos apreender a situação importante para o envolvimento na causa em que atua e os fatores considerados relevantes para ocupação de cargos de chefia dentro do movimento. Como indicadores, partimos de uma lista de questões postas aos entrevistados concernentes à forma como houve o contato inicial com a causa em que atuam - via participação em outros movimentos e associações, ou ainda via de amigos, familiares e colegas de trabalho. Podemos perceber que as redes informais compostas, sobretudo, por amigos, colegas de trabalho e familiares constituem um importante meio de acesso tanto na entrada na causa em que atua como para a intensidade do engajamento manifestada, principalmente, pelos níveis de participação e ocupação de cargos de chefia.

Segundo nos mostram Passy e Giugni (2001), é importante, na análise das redes, investigar tanto a natureza do laço que pretendemos mostrar da relação quanto o impacto que elas possam ter nos níveis e na intensidade da participação. Assim, as redes informais, aquelas compostas por laços de amizades, familiares e colegas de trabalho, têm efeitos significativos para entender os processos de recrutamento na defesa de certas causas, ou seja, na estrutura das oportunidades de participação dada pela conexão com os laços sociais. As redes têm a função de socialização, o que facilita um envolvimento nos movimentos sociais, contribuindo assim, de forma significativa, na participação individual. Desse modo, as redes não são apenas condição de participação, mas têm um efeito decisivo na intensidade do engajamento. De acordo com os autores citados, as redes têm três funções determinantes: primeiro, elas constituem estruturas de conexão que funcionam como oportunidades para participação; segundo, elas socializam os indivíduos nos temas de protesto; e, terceiro, contribuem para a construção da decisão de se tornar envolvido na causa. As redes sociais, portanto, contribuem tanto para entrada no engajamento quanto para a intensidade da participação.

\section{A CARREIRA DOS "ADVOGADOS DE CAUSAS"}

O exame da formação de um espaço engajado de atuação dos advogados deve destacar os per- 
cursos dos atores com vistas a identificar tanto as condições sociais, políticas e profissionais que tornam possível a um advogado consagrar sua vida profissional na defesa dos direitos humanos, quanto os princípios de identificação que marcam sua carreira. Nesse sentido, a análise das carreiras permite articular: lógicas objetivas, considerando para isso o conjunto das posições ocupadas e dos cargos conquistados; lógicas situacionais; ${ }^{10}$ e, por fim, as lógicas subjetivas (as reconversões ideológicas) que se misturam ao longo dos itinerários.

Além disso, a análise das carreiras permite evitar aquilo que Péchu (2001) chama de "hipótese da desclassificação", a qual consiste em perceber o investimento em recursos militantes apenas, como uma estratégia para evitar a desclassificação social e profissional. Mais do que isso, o exame das carreiras permite dar conta das formas de inserção social, dos espaços de socialização que contribuem para o engajamento na defesa de causas e as ressignificações do papel profissional. No nosso caso, demonstramos que o investimento na defesa dos direitos humanos, por parte dos advogados, não consiste apenas em uma estratégia para acumular relações suficientes, capazes de permitir um destaque no mundo do direito. Mas tal investimento se caracteriza, principalmente, por oferecer um novo sentido ao investimento profissional e por caracterizar uma reconversão ideológica.

Tomaremos aqui, como caso ilustrativo, o percurso de um dos advogados sergipanos que atua, na condição de profissional e militante, em uma entidade de defesa da questão racial e que oferece consultoria jurídica, palestras e seminários como estratégia de conscientização da comunidade negra. Além disso, é atualmente presidente da recém-constituída comissão de igualdade racial da $\mathrm{OAB}^{11}$, professor universitário e do curso de pósgraduação lato sensu em direito público de uma universidade particular de Sergipe.

${ }^{10}$ Esse é o caso das configurações sociais, políticas e profissionais que estruturam a oferta militante, assim como das situações que se apresentam aos profissionais, que podem ser estimuladoras para ingressar na defesa de causas e permanecer engajados (Collovald, 2002).

${ }^{11}$ Essa comissão foi constituída em novembro de 2011.
Defensor das políticas de cotas raciais e atuante na luta contra a discriminação racial, com inúmeros artigos publicados sobre o tema e pesquisas em curso, seu percurso social representa uma história de sucesso obtida por meio, sobretudo, dos investimentos escolares. Oriundo de uma família com dificuldades econômicas para manter os filhos na escola, esse advogado contou com a ajuda de um tio que o apadrinhou durante alguns anos de estudo, amparando-o no seu percurso escolar e custeando dois anos de escola particular durante o ensino fundamental. Segundo relata, "a primeira ação afirmativa da minha vida foi a ajuda desse tio". Formado em escolas públicas desde o primeiro grau, passando pela escola técnica, até a formação universitária, antes de cursar a faculdade de direito prestou vestibular duas vezes para medicina. As duas reprovações o fizeram desistir e investir no curso de direito. É no curso de direito que podemos observar as experiências mais significativas da sua carreira tanto no que diz respeito ao fato de proporcionar a entrada em espaços de defesa de causas, quanto de reorientar e dar um novo sentido para sua vida, proporcionado uma mudança nas visões de si e do mundo. Vale destacar que seu curso de direito foi realizado na Universidade Federal de Sergipe de 2000 a 2003. Tal curso possui, na sua grade de disciplinas, desde 1999, Direitos Humanos, além de outras, consideradas menos tradicionais no direito, como Direito Ambiental e Direito da Criança e do Adolescente. Portanto, o momento de realização do seu curso passa pela oferta dessas disciplinas, o que contribuiu para criar um espaço de oportunidade de investimento profissional nessa área.

Contudo, mais do que um espaço de formação, a universidade se constitui em uma das principais esferas de sociabilidade que se destaca na carreira desse advogado, uma vez que é no interior dela que ele passa a investir, concomitantemente, no movimento estudantil e na militância racial. Decorrem daí os laços principais, capazes de colocar o direito a serviço das causas raciais, e a elaboração de um sentido para o exercício da sua atuação engajada. No movimento estudantil teve uma 
participação importante, chegando a conquistar o cargo de coordenador do Centro Acadêmico Sílvio Romero, do curso de direito, da Universidade Federal de Sergipe. É nesse momento que ele começa a participar do movimento negro e de organizações não governamentais voltadas para a defesa dos direitos humanos. Esse centro acadêmico desempenhou, nos anos 1960 e 1970, um papel importante de rearticulação dos estudantes universitários, tendo uma participação na luta contra a ditadura. Sua existência antecede a criação da Universidade Federal de Sergipe (UFS), uma vez que estava vinculado à Faculdade de Direito de Sergipe, que depois foi integrada à UFS.

A inserção universitária e as experiências vivenciadas nesse espaço têm se apresentado como importantes meios de socialização na defesa de causas. Como espaço de formação acadêmica, mas também como espaço de múltiplas trocas, a vida universitária propicia aos alunos o contato com a participação, sobretudo por meio do movimento estudantil. Alguns estudos têm observado ${ }^{12}$ que o movimento estudantil, no decorrer nas décadas de 1990 e 2000, no Brasil, passou a absorver a temática dos movimentos sociais, como a questão racial, ambiental e a luta contra homofobia, não se limitando a uma atuação política partidária, como acontecia nos anos 1960-1970. Tal mudança promove novas formas de sociabilidade militante, tornando o movimento estudantil um dos principais canais de participação.

Além disso, as experiências vivenciadas como aluno contribuem para dar sentido a tais investimentos, orientando suas visões a respeito do "ser negro" na universidade. Segundo afirma, a experiência de ser negro na universidade teve um peso decisivo para sua inserção na militância, uma vez que a experiência na academia contribuiu para que verificasse o quanto os professores não conseguiam distinguir os alunos negros entre si, que eram quatro numa turma de 50 alunos. Dos quatro, apenas dois se formariam.

\footnotetext{
${ }^{12}$ Sobre isso ver: Mische (1997).
}

Ela (a professora) não conseguia perceber que tínhamos um rosto peculiar e próprio, além da pele negra comum. Só depois percebi o quanto ela destruía a minha identidade e autoestima [...]. A discriminação no Brasil quase nunca é explícita. Somos culturalmente trabalhados para evitar conflitos (Sindsep,PE, 2009).

Essa experiência é apresentada como fundamental para despertar a percepção a respeito da discriminação no espaço acadêmico e permitir perceber as dificuldades que enfrenta a população negra no que diz respeito ao direito à identidade étnico-racial. Tal vivência, durante o período de quatro anos do curso acadêmico, desempenha um papel importante na interpretação subjetiva que guia sua conduta, constituindo um momento importante de ajustamento e remanejamento subjetivo.

Durante o curso, inseriu-se em redes formais, como a Rede Nacional de Assessoria Jurídica Universitária (RENAJU), com o objetivo de qualificar sua formação. Tal rede tem por objetivo prestar assessoria jurídica e reunir advogados e militantes interessados em desenvolver atividades de educação popular. Além de participar como organizador de eventos, como o Encontro Nacional de Estudos Jurídicos, o Encontro dos Estudantes de Direito e o Encontro de Assessoria Jurídica Universitária.

Assim, o engajamento, inicialmente manifestado no movimento estudantil, depois na defesa das causas raciais e na defesa dos direitos humanos, constitui uma experiência reestruturante, que permite dar sentido à sua atuação profissional e reorienta as possibilidades de investimento. $\mathrm{O}$ engajamento aparece em momentos de ruptura ou de reorientação biográfica e identitária.

Além disso, investiu amplamente na sua carreira acadêmica, realizando cursos de pós-graduação em nível de especialização, mestrado e doutorado em várias frentes do direito, desde o direito público até a qualificação em direito constitucional. Concluiu o mestrado em direito público na Universidade Federal da Bahia e, como bolsista do Programa Internacional de Bolsas de Pós-graduação da Fundação Ford (Internacional Fellowship Program - IFP), realizou, ainda, mestrado-sanduíche no Centro de Estudos Sociais (CES) da Uni- 
versidade de Coimbra. Atualmente, é doutorando em teoria do direito na PUC do Rio de Janeiro.

Ao mesmo tempo, seus trabalhos de graduação e pós-graduação foram pautados pela preocupação com o direito e as causas raciais. Isso pode ser observado nas temáticas que envolviam desde seu trabalho de conclusão de curso até a sua tese de doutorado. Na graduação suas preocupações se iniciam com as políticas afirmativas e cotas na universidade. Já sua dissertação de mestrado voltou-se para o discurso do judiciário sobre as ações afirmativas e sua tese, ainda em andamento, focaliza o papel do judiciário na construção da identidade negra. Como se pode observar, sua formação não está desconectada de sua preocupação com a questão racial e do intenso investimento no direito como alternativa para resolução de conflitos e atuação na defesa de causas sociais.

Tais investimentos concomitantes, no movimento racial e no movimento estudantil, permitiram-lhe um amplo leque de possibilidades profissionais e de militância. Logo após a conclusão do seu curso de graduação, intensificou seus investimentos na defesa dos direitos humanos e raciais, atuando, concomitantemente, como articulador do Movimento Nacional de Direitos Humanos em Sergipe, como coordenador do Fórum de Direitos Humanos de Sergipe e da Sociedade Afro-Sergipana de Estudos e Cidadania (SACI), na qualidade de diretor do núcleo de direitos humanos e raça. Tais atuações foram sendo conquistadas via indicação de amigos do movimento negro.

Vale ressaltar que a ONG SACI, uma das mais importantes associações no cenário do movimento negro sergipano, concentrava, no final dos anos 1990, um orçamento anual de $\mathrm{R} \$ 200.000,00$. Além disso, essa entidade, que desfrutava de importante visibilidade pública e acionava um conjunto de equipes técnicas, foi uma das principais articuladoras do Fórum de Entidades Negras do Estado de Sergipe. A desarticulação da SACI desencadeou uma desarticulação do Fórum que, já no final dos anos 1990, não conseguiu mais quorum para realizar suas reunióes. Tal desarticulação se deu, em grande parte, pela filiação políti- ca partidária dos militantes da SACI, que foram compor os quadros administrativos do governo do Estado de Sergipe, com destaque para a Secretaria Especial de Políticas de Promoção da Igualdade Racial (SEPPIR). As clivagens e os confrontos ocasionaram uma situação de fragmentação e de pouca concorrência entre as entidades, o que exerceu um efeito decisivo nas possibilidades de emergência de novos discursos sobre a questão racial e seus atores (Neves, 2000; Souza, 2009). A entrada desse advogado, em meados da década de 2000, ocorre no momento em que a SACI estava passando por uma crise interna provocada por tais clivagens: de um lado, aqueles que estavam saindo da instituição para atuar no Estado; de outro, aqueles que se posicionavam contrários ao investimento político partidário do movimento. Essa configuração impossibilitou o investimento profissional no interior do movimento, o qual estava fragmentado, não conseguindo oferecer formas de atuação profissional.

Sua inserção múltipla, no espaço profissional e no espaço da militância da causa racial, permitiu-lhe acumular recursos fundamentais, os quais vão desde relações estabelecidas no interior do movimento até o conhecimento e a apropriação de um discurso engajado, que puderam ser mobilizados na profissão e implantados no movimento de defesa dos direitos raciais. Além disso, a experiência universitária e o investimento em entidades de defesa da causa humanitária lhe permitiram orientar os investimentos profissionais e dar um novo sentido a ele. Ao circular em várias posições, organizações, fóruns, movimentos sociais, universidades, ele enriquece suas competências e intensifica seus referenciais políticos.

Atualmente, além de exercer a advocacia, como assessor jurídico voluntário de uma organização não governamental voltada para a defesa da condição racial, atua como professor universitário do curso de direito de várias faculdades particulares da cidade de Aracaju. Participa também da Associação Brasileira de Pesquisadores Negros e da Associação Brasileira de Pesquisadores pela Justiça Social. É, ainda, colunista no Afropress, agência de informação multi-étnica. 


\section{CONSIDERAÇÕES FINAIS}

De um lado, procuramos destacar, neste artigo, a importância de se analisar o contexto social e histórico a partir do qual se produzem os engajamentos. De outro, destacamos a pertinência de um exame das condições objetivas que podem servir como alavancas para o investimento no universo de causas. E, por fim, procedemos ao exame dos "engajamentos de si" como um dos principais aspectos a ser levado em consideração nas pesquisas atuais.

Essa preocupação, em três frentes, nos permitiu mostrar que as configurações profissionais sucitam níveis de engajamento, uma vez que elas criam diferentes ciclos de mobilização política. Nesse sentido, pode-se dizer que o momento de abertura política e de redemocratização da política brasileira, assim como a organização do processo constituinte, decorrente de tal abertura, a qual se iniciou nos anos 1980 para realização da nova Constituição brasileira, criou as condições tanto para emergência de novos atores na política nacional quanto para novas formas de mobilização do espaço jurídico. Dentre esses novos atores, estão os movimentos sociais, que se diversificaram nesse período, contando com quadros de militantes oriundos de várias profissões e com diferentes formações universitárias. Esses novos atores, sobretudo os advogados, sentiram-se autorizados a mobilizar a lei em favor das causas que empreendiam, criando, portanto, verdadeiros "ciclos de engajamento".

Esse contexto da redemocratização diversifica os vínculos dos profissionais com a política, tendo em vista que, nesse momento, eles passam a se interessar não somente pela luta contra a ditadura e pelos direitos políticos, mas por uma diversidade de causas que favorecem as trocas e colaborações entre profissionais e militantes. Tal situação contribuiu para desencadear possibilidades de associação entre saberes políticos e saberes profissionais, ampliando a intensificação das esferas de ação jurídica. Desse modo, os advogados podem se sentir autorizados a desempenhar o papel de intermediários na expressão dos descontenta- mentos. Além disso, os grupos organizados de advogados também desempenham um papel fundamental, conforme a expressão tomada de empréstimo de Boltanski (1982), no "trabalho de mobilização" em torno de problemáticas comuns. O desenvolvimento de atuações e espaços como esses e de posições a serem ocupadas contribui para orientar as expectativas e projetos quanto ao exercício da profissão.

Ao mesmo tempo, a análise das condições objetivas do engajamento dos advogados permitiu demonstrar dois aspectos centrais: a situação profissional como determinante do engajamento na defesa de causas e a inserção dos profissionais em múltiplas esferas como uma forma de ampliar os espaços de investimento. Por fim, o exame das carreiras permitiu identificar o peso da socialização profissional, sobretudo do universo acadêmico, como um momento-chave nas modificações e percepções sobre o mundo profissional. Essa experiência permite aos indivíduos realizar o trabalho de ajustamento e confronto com a realidade.

Desse modo, os investimentos dos advogados na defesa dos direitos humanos, ao mesmo tempo que possibilitam uma estrutura de oportunidades profissionais, contribuem para formulação de um sentido para o exercício profissional. Devido à configuração do mercado de trabalho na área do direito, da intensa concorrência, os jovens formandos, sem recursos que lhes permitam montar seu próprio escritório e investir na advocacia privada, são colocados diante da situação de ter de criar seus próprios empregos. A limitada opção profissional os conduz ao investimento na defesa de causas como uma estratégia de sobrevivência no mercado de empregos. Assim, a experiência militante é facilmente reconvertível no mercado. Contudo, mais do que apenas uma inserção no mercado e uma retribuição profissional da militância, tal investimento tem um peso decisivo na reestruturação do sentido atribuído à profissão, contribuindo para mantê-los no espaço profissional. Isso significa afirmar que o engajamento na defesa dos direitos humanos constitui uma experiência reestruturante, que permite aos advoga- 
dos darem uma coerência à sua atuação profissional, contribuindo para que assumam um papel social valorizante, de importante utilidade e visibilidade social.

Recebido para publicação em 31 de janeiro de 2013 Aceito em 26 de julho de 2013

\section{REFERÊNCIAS}

ABONG.Associação Brasileira de Oganizações Não Gover namentais. Panorama das Associadas. São Paulo: 2010.

AGRIKOLIANSKI, E. Les usages protestaires du droit. In AGRIKOLIANSKI, E. et al. Penser les mouvements sociaux Paris: La Découverte, 2010. p. 225-243.

BOLTANSKI, Luc. Les cadres. Paris: Les Éditions de Minuit. 1982.

BRITO E SILVA, V. O movimento nacional de direito humanos e a questão da violência institucionalizada. 1999. 136f. Dissertação (Mestrado em Serviço Social) Programa de Pós Graduação em Política Social da UNB. Brasília: UNB, 1999.

COLLOVALD, A. Pour une sociologie des carrières morales. In: COLLOVALD, A. L'humanitaire ou le management des dévouements. Paris: Presses Universitaires de Rennes, 2002. p. 177-225.

CORADINI, O. L. Relações profissionais e disputas eleitorais. In: BARREIRA, C; PALMEIRA, M. Política no Brasil. Visões de antropólogos. Rio de Janeiro: Relume Dumará, 2006. p. 267-297.

ENGELMAN, F. Internacionalização e ativismo judicial as causas coletivas. Lua Nova: revista de Cultura e Política, São Paulo, CEDEC, n. 69, p. 123-146, 2006.

FILLIEULE, O. Propositions pour une analyse processuelle de l'engagement individuel. Revue Francaise de Science Politique, Paris, v. 51, n. 1-2, p. 199-215, fév./avril. 2001.

RANCA, A.S.D.S. A Conversão de Dom José Brandão de Castro: a ação social de mediadores religiosos na Diocese de Propriá. 2004. 151f. Dissertação (Mestrado em Sociologia) - Programa de Pós graduação em Sociologia, UFPE. Recife: 2004.

GARLANT, D. Q. Formation et reformulation d'une cause. Le cas des droits de l'homme au Chili, de la dictature à 62 , n. 16, p. 165-190, 2003.

GAXIE, D. Rétributions du militantisme et paradoxes de
MÉON, J. M. Logiques e couts d'um investissement militant. La croisade de Fredric Wertham contre lês comic books: la mise em scéne d'une psychiatrie sociale et engagée. In: HAMMAN, P. et al. Disccours Savants, discours militants: mélange des genres. Paris: L'Harmattan, 2002. p. 225-250.

MISCHE, A. De estudantes a cidadãos. Redes de jovens e participação política. Revista Brasileira de Educação, São Paulo, n. 5/6, p. 134-150, 1997.

NEVES, P. S. C. A questão racial em Sergipe: visões de militantes e não militantes. In: ENCONTRO ANUAL da ANPOCS, 14., 2000, Caxambu. Anais... Caxambu: ANPOCS, 2000.

OLIVEIRA, L. Violation des droits de l'homme et redemocratisation au Brésil. Droit et Societé, Paris, n. 22 p. 447-463, 1992.

OLIVEIRA, W. J. F. Abertura política, militância múltipla e proliferação de protestos públicos em defesa de causas ambientais. Cadernos CERU, São Paulo, v. 20, p. 223239, 2009.

PASSY, F.; GIUGNI, M. Social networks and individual perceptions: explaining differential participation in social movements. Sociological Forum, [S.1.], v. 16, n. 1, p. 123153, 2001.

PÉCHU, C. Les Générations militantes à droit au logement. Revue Française de Science Politique, Paris, v. 51, n. 12, p. 73-103, fév./avr. 2001

PETRARCA, F. R.; NEVES, C. E. B. Direitos humanos se conquistam na luta: igualdade racial, ativismo jurídico e defesa de causas coletivas no Rio Grande do Sul. Sociedade e Estado, Brasília, UNB, v. 26, n. 1, p. 151-173, 2011.

SAWICKI, F; SIMÉANT, J. Inventário da sociologia do engajamento militante: nota crítica sobre algumas tendências recentes dos trabalhos franceses. Sociologias, Porto Alegre, UFRGS, v. 13, n. 28, p. 200-255, 2011.

SIMÉANT, J. ONG et humanitaire. In: humanitaire. Paris: L'Harmattan, 2004. p. 9-34.

ONG et

SINDSEP. PERNAMBUCO. 2009. Disponível em: http:// www.sindseppe.com.br/v2009/ conteudo/ garra_diario.php?cont $=$ noticias\&cod $=24542009$.

SOUSA, R. S. Filantropia e participação política no movimento do combate ao câncer infanto-juvenil em Sergipe. 2010. Dissertação (Mestrado em Sociologia) - Núcleo de Pós-Graduação e Pesquisa em Ciências Sociais. Universidade Federal de Sergipe. São Cristóvão, SE: UFSE, 2010.

SOUZA, M. E. S. Militância negra em Sergipe: investimentos e estratégias individuais. 2009. 20f. Monografia (Conclusão de curso Bacharelado em Ciências Sociais) - Universidade Federal de Sergipe. São Cristovão, SE: UFS, 2009.

VECCHIOLI, V. A luta pelo direito: engajamento militante e profissionalização dos advogados na causa pelos direitos humanos na Argentina. 2006. 414f. Tese (Doutorado em Antropologia) - Programa de Pós-Graduação em Antropologia Social, Universidade Federal do Rio de Janeiro, 2006 . 


\section{THE FIGHT FOR HUMAN RIGHTS: profissionalization of causes and politization of rights}

\section{Fernanda Rios Petrarca}

This paper examines the relationship between the professional practice of law and militant investments in human rights' defense. On one hand it examines the collective and situational logics that configure the militant offer in the professional space of law and, on the other hand, the individual careers. It focuses both on the objective dimension, or namely, the set of social, political and professional resources that lawyers have at their disposal, and on their subjective logics that encompass the ideological redefinition of the profession. The methodology adopted consisted of the use of surveys and biographic interviews carried out with lawyers active in human rights in Aracaju. This work shows that the experience with human rights commitment plays a decisive role in professional identification.

KEY wORDS: Human rights. Professional investment. Legal activism. Social causes. Commitment.

\section{LA LUTTE POUR LES DROITS DE L'HOMME: professionalisation de causes et politisation du droit}

\section{Fernanda Rios Petrarca}

Cet article analyse la relation qui existe entre la pratique professionnelle du droit et les investissements de militants pour la défense des droits de l'homme. Il s'agit d'examiner, d'une part, les logiques collectives et situationnelles qui configurent l'offre militante dans l'espace professionnel du droit et, d'autre part, les carrières individuelles en se concentrant autant sur la dimension objective, c'est-à-dire sur l'ensemble des ressources sociales, politiques et professionnelles dont disposent les avocats, que sur sa logique subjective qui suppose une redéfinition idéologique de la profession. La méthodologie adoptée a consisté à mener des questionnaires et à réaliser des entretiens biographiques avec les avocats qui travaillent dans le domaine des droits de l'homme à Aracaju. Ce travail permet de démontrer qu'une expérience dans l'engagement pour la défense des droits de l'homme joue un rôle décisif dans l'identification professionnelle.

Mots-Clés: Droits de l'Homme. Investissement professionnel. Activisme juridique. Causes sociales. Engagement

Fernanda Rios Petrarca - Doutora em sociologia. Professora adjunta da Universidade Federal de Sergipe. Bolsista produtividade nível 2 do CNPq, atua e tem experiência na área de Sociologia e Sociologia Política, com ênfase nos seguintes temas: atuação profissional, usos da formação universitária, jornalismo. Principais publicações: Ativismo jurídico e usos militantes do direito na luta pela igualdade racial. Revista de Antropologia (USP. Impresso), 2013; Construção do Estado, esfera política e profissionalização do jornalismo no Brasil. Revista de Sociologia e Política (UFPR. Impresso), v. 18, p. 81-94, 2010; Direitos Humanos se conquistam na luta: igualdade racial, ativismo jurídico e defesa de causas coletivas no Rio Grande do Sul. Sociedade e Estado (UnB. Impresso), v. 26, p. 151-173, 2011. 